UDC 519.8

Вестник СПбГУ. Прикладная математика. Информатика... 2021. Т. 17. Вып. 1

MSC 90C33

\title{
Non-linear optimization for continuous travel demand estimation*
}

\author{
A. P. Raevskaya, A. Y. Krylatov \\ St. Petersburg State University, 7-9, Universitetskaya nab., St. Petersburg, \\ 199034, Russian Federation
}

For citation: Raevskaya A.P., Krylatov A. Y. Non-linear optimization for continuous travel demand estimation. Vestnik of Saint Petersburg University. Applied Mathematics. Computer Science. Control Processes, 2021, vol. 17, iss. 1, pp. 40-46.

https://doi.org/10.21638/11701/spbu10.2021.104

Models and methods of traffic distribution are being developed by researchers all over the world. The development of this scientific field contributes to both theory and practice. In this article, the non-linear optimization of traffic flow re-assignment is examined in order to solve continuously the travel demand estimation problem. An approach has been developed in the form of computational methodology to cope with the network optimization problem. A uniqueness theorem is proved for a certain type of road network. Explicit relations between travel demand and traffic flow are obtained for a single-commodity network of non-intersecting routes with special polynomial travel time functions. The obtained findings contribute to the theory and provide a fresh perspective on the problem for transportation engineers.

Keywords: travel demand estimation, traffic assignment problem, non-linear optimization, bi-level optimization.

1. Introduction. Estimation of traffic flows on the roads of urban areas requires determination of the rules by which drivers choose their routes. The methodological basis for the traffic assignment is presented by behavioral principles. The most popular principle is formulated by [1]: the journey times in all actually used routes are equal and less than those that would be experienced by a single vehicle on any unused route.

In other words, no driver can unilaterally reduce his/her travel costs by shifting to another route. Such a principle of route choice is known as Wardrop's first principle or user equilibrium behavioral principle. The assignment of traffic flows according to the Wardrop's first principle corresponds to a competitive non-cooperative equilibrium assuming complete selfishness of users [2]: everyone wants to reach the destination point as fast as possible and chooses the route that will lead to the lowest potential travel costs (temporary, financial, moral, etc.) [3, 4]. This principle fully takes the factor of mutual influence of users into account, and its essence can be expressed as follows: in case of equilibrium traffic assignment, no user may lower his/her transportation cost through unilateral action [5]. In the paper, we consider the Wardrop's first principle as the basic behavioral patterns of users within a particular network.

The first mathematical formulation of this principle was obtained by M. Beckman et al. [6]. Subsequently, this mathematical model has become a classic [7], and today it appears to be one of the key elements in the traffic flow theory [8]. Besides, it should be mentioned that the traffic assignment problem has a form of an optimization program if and only if the performance time of a link is depended on the flow of this link solely [9].

* The work was supported by the Russian Science Foundation (project N 20-71-00062).

(C) St. Petersburg State University, 2021 
2. Traffic flow re-assignment in network optimization problems. Let us consider a network, presented by the connected directed graph $G=(V, E)$ consisting of sequentially numbered vertices $V,|V|=\mathfrak{v}$ and sequentially numbered edges $E,|E|=\mathfrak{m}$. We will use the following notation: $W$ is the set of pairs of vertices (an origin and a destination), $W \subseteq V \times V,|W|=\mathfrak{n}, w \in W ; R^{w}$ is the set of routes between the origindestination pair $w, R=\left\{R^{w}\right\}_{w \in W},|R|=\mathfrak{r} ; x_{e} \geqslant 0$ is the traffic flow through the edge $e \in E, x=\left(\ldots, x_{e}, \ldots\right)^{\mathrm{T}} ; t_{e}\left(x_{e}\right)$ is a smooth increasing function that models the travel time (delay) of the flow $x_{e}, x_{e} \geqslant 0$, through the congested edge $e, e \in E ; f_{r}^{w} \geqslant 0$ is the traffic flow through the route $r \in R^{w}$ between the OD-pair $w, f^{w}=\left\{f_{r}^{w}\right\}_{r \in R^{w}}$ and $f=\left\{f^{w}\right\}_{w \in W} ; F^{w}>0$ is the travel demand between a given OD-pair $w \in W$, $\sum_{r \in R^{w}} f_{r}^{w}=F^{w}, F=\left\{F^{w}\right\}_{w \in W} ; \delta_{e, r}^{w}$ is an indicator,

$$
\delta_{e, r}^{w}= \begin{cases}1, & \text { if the edge } e, e \in E, \text { lies along the route } r, r \in R^{w} ; \\ 0, & \text { otherwise. }\end{cases}
$$

Formally, within the introduced notation, the user equilibrium in a road network is such an assignment of travel demand $F^{w}, w \in W$, between available routes $f$, that

$$
\sum_{e \in E} t_{e}\left(x_{e}\right) \cdot \delta_{e, r}^{w}\left\{\begin{array}{ll}
=\mathfrak{t}^{w}, & \text { if } f_{r}^{w}>0, \\
\geqslant \mathfrak{t}^{w}, & \text { if } f_{r}^{w}=0,
\end{array} \quad \forall r \in R^{w},\right.
$$

subject to

$$
x_{e}=\sum_{w \in W} \sum_{r \in R^{w}} f_{r}^{w} \cdot \delta_{e, r}^{w} .
$$

In formula (1) $\mathfrak{t}^{w}>0$ is the equilibrium travel time through any actually used route between the OD-pair $w, w \in W[1,6]$. Let us introduce a vector $\mathfrak{t}=\mathfrak{t}_{\mathfrak{n} \times 1}=\left(\ldots, \mathfrak{t}^{w}, \ldots\right)^{\mathrm{T}}$, $w \in W$.

For the first time, the traffic assignment problem was formulated by M. Beckman et al. $[6,10]:$

$$
Z\left(x^{*}\right)=\min _{x} \sum_{e \in E} \int_{0}^{x_{e}} t_{e}(u) d u
$$

subject to

$$
\begin{aligned}
& \sum_{r \in R^{w}} f_{r}^{w}=F^{w} \quad \forall w \in W \\
& f_{r}^{w} \geqslant 0 \quad \forall r \in R^{w}, w \in W
\end{aligned}
$$

with definitional constraints

$$
x_{e}=\sum_{w \in W} \sum_{r \in R^{w}} f_{r}^{w} \delta_{e, r}^{w} \quad \forall e \in E .
$$

It is proved that the solution $x^{*}$ of the optimization problem $(2)-(5)$ is the user equilibrium of Wardrop [6, 7].

3. Travel demand estimation. Travel demand values are input data in the problem (2)-(5). In other words, in the traffic assignment problem, it is required to find the equilibrium values of arc flows from the known set of OD-pairs and known values (positive) of travel demand between these pairs. It seems natural to understand the inverse problem 
to the traffic assignment as a problem of finding the OD-pairs and the volumes of travel demand between them in compliance with the given values of arc flows of the road network. Let us introduce the set $\mathfrak{F}$,

$$
\mathfrak{F}=\left\{F \mid F^{w} \geqslant 0 \quad \forall w \in V \times V\right\},
$$

the set $\mathfrak{X}(F)$ for all $F \in \mathfrak{F}$,

$$
\begin{aligned}
& \mathfrak{X}(F)=\left\{x \mid x_{e}=\sum_{w \in V \times V} \sum_{r \in R^{w}} f_{r}^{w} \delta_{e, r}^{w} \quad \forall e \in E,\right. \\
& \left.\sum_{r \in R^{w}} f_{r}^{w}=F^{w}, f_{r}^{w} \geqslant 0 \quad \forall r \in R^{w}, w \in V \times V\right\},
\end{aligned}
$$

and the mapping $\mathfrak{Z}, \mathfrak{Z}: \mathfrak{F} \rightarrow \mathfrak{R}_{+}^{\mathfrak{m}}$, where $\mathfrak{R}_{+}^{\mathfrak{m}}$ is nonnegative orthant of vector space of dimension $\mathfrak{m}$, presented by the function

$$
\mathfrak{Z}(F)=\arg \min _{x \in \mathfrak{X}(F)} \sum_{e \in E} \int_{0}^{x_{e}} t_{e}(u) d u .
$$

The mapping $\mathfrak{Z}$ establishes a relationship between equilibrium traffic flow assignment patterns $x \in \mathfrak{X}$ and feasible travel demand patterns $F \in \mathfrak{F}$.

Due to the mapping $\mathfrak{Z}(F), F \in \mathfrak{F}$, the travel demand estimation problem can be formulated in a form of bi-level optimization program as follows [11]:

$$
\min _{F \in \mathfrak{F}}\|\mathfrak{Z}(F)-\bar{x}\|
$$

subject to

$$
\mathfrak{Z}(F)=\arg \min _{x \in \mathfrak{X}(F)} \sum_{e \in E} \int_{0}^{x_{e}} t_{e}(u) d u .
$$

Theorem 1. The travel demand estimation problem (6), (7) for the single-commodity network with disjoint routes can be relaxed so:

$$
\min _{F \geqslant 0}\left\|x_{i}-\bar{x}_{i}\right\|
$$

subject to

$$
x=\arg \min _{x} \sum_{s=1}^{n} \int_{0}^{x_{s}} t_{s}(u) d u
$$

on a set of restrictions

$$
\sum_{s=1}^{n} x_{s}=F, \quad x_{s} \geqslant 0 \quad \forall s=\overline{1, n},
$$

for any $i$ from the set of actually used routes.

P r o o f . Let us consider the problem of traffic assignment on the network of disjoint routes:

$$
\min _{x} \sum_{s=1}^{n} \int_{0}^{x_{s}} t_{s}(u) d u
$$


subject to

$$
\begin{gathered}
\sum_{s=1}^{n} x_{s}=F, \\
x_{s} \geqslant 0 \quad \forall s=\overline{1, n} .
\end{gathered}
$$

The (11)-(13) problem is a convex optimization problem, and therefore it has a unique solution for any fixed $F$. Moreover, if $\tilde{F} \neq \hat{F}$, then corresponding equilibrium assignment of flows $\tilde{x}$ and $\hat{x}$ are such, that $\tilde{x} \neq \hat{x}$.

Let us suppose that there are $\tilde{F}$ and $\hat{F}$ such that $\tilde{F}<\hat{F}$, but there is an index $k$, $1 \leqslant k \leqslant n$, such that $\hat{x}_{k} \leqslant \tilde{x}_{k}$. Solutions of the problem (11)-(13) for $\tilde{F}$ and $\hat{F}$ satisfy the following conditions: $t_{i}\left(\tilde{x}_{i}\right)=\tilde{\mathfrak{t}}$, if $\tilde{x}_{i}>0$, and $t_{i}\left(\hat{x}_{i}\right)=\hat{\mathfrak{t}}$, if $\hat{x}_{i}>0$ (i. e. for all actually used routes). In addition, the functions $t_{i}\left(x_{i}\right) \forall i=\overline{1, n}$ are increasing. Therefore, if there exists an index $k$ such that $\hat{x}_{k} \leqslant \tilde{x}_{k}$, then $t_{k}\left(\hat{x}_{k}\right) \leqslant t_{k}\left(\tilde{x}_{k}\right)$, which means $\hat{\mathfrak{t}} \leqslant \tilde{\mathfrak{t}}$ and $\hat{x}_{i} \leqslant \tilde{x}_{i}$ for all actually used routes, which leads to

$$
\hat{F}=\sum_{i=1}^{n} \hat{x}_{i} \leqslant \sum_{i=1}^{n} \tilde{x}_{i}=\tilde{F}
$$

We cross a contradiction. Thus, if $\tilde{F}>\hat{F}$, then $\tilde{x}_{i}>\hat{x}_{i}$ for all actually used routes $i=\overline{1, n}$. In other words, by the known traffic on any arc, one can uniquely determine travel demand $F$.

Theorem 1 is proved.

Thus, in case of a single-commodity network of disjoint routes with non-linear travel time functions, the traffic value on a single arc is sufficient in order to reconstruct travel demand value uniquely.

Let us introduce functions $a_{i}\left(x_{i}\right)=t_{i}\left(x_{i}\right)-t_{i}^{\prime}\left(x_{i}\right) x_{i}$ and $b_{i}\left(x_{i}\right)=t_{i}^{\prime}\left(x_{i}\right)$ for $i=\overline{1, n}$. An effective way to solve the problem (8)-(10) can be based on the following methodology: continuous changing of $F$ leads to continuous changing of $x_{i}, i=\overline{1, n},(q+1)$ iteration as follows [12]:

1. To reindex $k_{q}$ components $x^{q}$ and $t\left(x^{q}\right)$ so that

$$
a_{1}\left(x_{1}^{q}\right) \leqslant a_{2}\left(x_{2}^{q}\right) \leqslant \ldots \leqslant a_{k}\left(x_{k}^{q}\right) .
$$

2. To find $k_{q+1} \leqslant k_{q}$ (amount of non-zero components $x^{q+1}$ ) from the condition

$$
\sum_{i=1}^{k_{q+1}} \frac{a_{k_{q+1}}\left(x_{k_{q+1}}^{q}\right)-a_{i}\left(x_{i}^{q}\right)}{b_{i}\left(x_{i}^{q}\right)} \leqslant F<\sum_{i=1}^{k_{q+1}} \frac{a_{k_{q+1}+1}\left(x_{k_{q+1}+1}^{q}\right)-a_{i}\left(x_{i}^{q}\right)}{b_{i}\left(x_{i}^{q}\right)} .
$$

3. To calculate $x^{q+1}$ :

$$
\begin{gathered}
x_{i}^{q+1}=\frac{1}{b_{i}\left(x_{i}^{q}\right)} \frac{F+\sum_{s=1}^{k_{q+1}} \frac{a_{s}\left(x_{s}^{q}\right)}{b_{s}\left(x_{s}^{q}\right)}}{\sum_{s=1}^{k_{q+1}} \frac{1}{b_{s}\left(x_{s}^{q}\right)}}-\frac{a_{i}\left(x_{i}^{q}\right)}{b_{i}\left(x_{i}^{q}\right)}, \quad i=\overline{1, k_{q+1}}, \\
x_{i}^{q+1}=0, \quad i=\overline{k_{q+1}, n} .
\end{gathered}
$$

4. To check the fulfilment of the termination criterion

$$
\sum_{i=1}^{k_{q+1}-1}\left|t_{i}\left(x_{i}^{q+1}\right)-t_{i+1}\left(x_{i+1}^{q+1}\right)\right|<\epsilon .
$$

In other words, the problem (8)-(10) of bi-level optimization does have a specific descent direction. 
Theorem 2. Consider a single-commodity network of disjoint routes with the link performance functions $t_{i}\left(x_{i}\right)=a_{i}+b_{i}\left(x_{i}\right)^{m}, m>1, a_{i} \geqslant 0, b_{i}>0$, for all $i=\overline{1, n}$. The travel demand $F$ is equal to

$$
F=\sum_{i=1}^{k} \sqrt[m]{\frac{b_{l}\left(x_{l}\right)^{m}+a_{l}-a_{i}}{b_{i}}} \quad \forall l=\overline{1, k}
$$

where $k$ satisfies

$$
a_{1} \leqslant \ldots \leqslant a_{k}<a_{l}+b_{l}\left(x_{l}\right)^{m} \leqslant a_{k+1} \leqslant \ldots \leqslant a_{n} .
$$

P r o o f . Lagrangian of the problem (9), (10) is

$$
L=\sum_{i=1}^{n} \int_{0}^{x_{i}} t_{i}(u) d u+\mathfrak{t}^{1}\left(F-\sum_{i=1}^{n} x_{i}\right)+\sum_{i=1}^{n} \xi_{i}\left(-x_{i}\right),
$$

where $\mathfrak{t}^{1}$ and $\xi_{i} \geqslant 0, i=\overline{1, n}$, are multipliers of Lagrange. Partial derivatives of the Lagrangian with respect to $x_{i}, i=\overline{1, n}$, must be equal to zero

$$
\frac{\partial L}{\partial x_{i}}=t_{i}\left(x_{i}\right)-\mathfrak{t}^{1}-\xi_{i}=0
$$

that leads to

$$
t_{i}\left(x_{i}\right)=\mathfrak{t}^{1}+\xi_{i}
$$

The complementary slackness condition requires the equalities $\xi_{i} x_{i}=0$ be true for all $i=\overline{1, n}$. In this case, if $x_{i}>0$, then $\xi_{i}=0$. If $x_{i}=0$, then $\xi_{i} \geqslant 0$. According to the Lagrangian function the Khun-Tucker conditions are both sufficient and necessary. In this case (14) is defined as

$$
t_{i}\left(x_{i}\right)\left\{\begin{array}{ll}
=\mathfrak{t}^{1}, & \text { if } x_{i}>0, \\
\geqslant \mathfrak{t}^{1}, & \text { if } x_{i}=0,
\end{array} \quad \forall i=\overline{1, n}\right.
$$

wherefrom

$$
a_{i}+b_{i}\left(x_{i}\right)^{m}\left\{\begin{array}{ll}
=\mathfrak{t}^{1}, & \text { if } x_{i}>0, \\
\geqslant \mathfrak{t}^{1}, & \text { if } x_{i}=0,
\end{array} \quad \forall i=\overline{1, n} .\right.
$$

Without loss of generality we assume that $x_{i}>0$ for $i=\overline{1, k}, k \leqslant n$. According to (10) and (15) we have

$$
\sum_{i=1}^{n} x_{i}=\sum_{i=1}^{k} x_{i}=\sum_{i=1}^{k} \sqrt[m]{\frac{\mathfrak{t}^{1}-a_{i}}{b_{i}}}=F
$$

or

$$
\sum_{i=1}^{n} x_{i}=\sum_{i=1}^{k} x_{i}=\sum_{i=1}^{k} \sqrt[m]{\frac{b_{l}\left(x_{l}\right)^{m}+a_{l}-a_{i}}{b_{i}}}=F \quad \forall l=\overline{1, k}
$$

Moreover, according to (15), for all unused routes $b_{l}\left(x_{l}\right)^{m}+a_{l} \leqslant a_{i}$, while for used routes $b_{l}\left(x_{l}\right)^{m}+a_{l} \geqslant a_{i}$, that leads to

$$
a_{1} \leqslant \ldots \leqslant a_{k}<a_{l}+b_{l}\left(x_{l}\right)^{m} \leqslant a_{k+1} \leqslant \ldots \leqslant a_{n} .
$$

Theorem 2 is proved. 
Corollary. Consider a network of parallel routes: $t_{i}\left(x_{i}\right)=a_{i}+b_{i} x_{i}, a_{i} \geqslant 0, b_{i}>0$, for all $i=\overline{1, n}$. The mapping $\mathfrak{G}$ function has the following explicit form:

$$
\mathfrak{G}(x)=\left(a_{l}+b_{l} x_{l}\right) \sum_{s=1}^{k} \frac{1}{b_{s}}-\sum_{s=1}^{k} \frac{a_{s}}{b_{s}} \quad \forall l=\overline{1, k},
$$

where $k$ is defined as

$$
a_{1} \leqslant \ldots \leqslant a_{k}<a_{l}+b_{l} x_{l} \leqslant a_{k+1} \leqslant \ldots \leqslant a_{n}
$$

Therefore, for a single-commodity network of disjoint routes with certain polynomial travel time functions, the relations between travel demand and traffic flow can be obtained explicitly.

4. Conclusion. Within the paper, non-linear optimization for efficient re-assignment traffic flows, under continuous changing of travel demand values, was studied. The approach was given in the form of computational methodology to cope with the network optimization problem. The uniqueness theorem was proved for a certain type of road network. Explicit relations between travel demand and traffic flow was obtained for a singlecommodity network of disjoint routes with certain polynomial travel time functions. The obtained findings contribute to the theory and give fresh managerial insights for traffic engineers.

\section{References}

1. Wardrop J. Some theoretical aspects of road traffic research. Proceedings of the Institute of Civil Engineers, 1952, vol. 1(3), pp. 325-362.

2. Krylatov A., Zakharov V., Malygin I. Competitive traffic assignment in road networks. Transport and Telecommunication, 2016, vol. 17(3), pp. 212-221.

3. Krylatov A., Zakharov V. Competitive traffic assignment in a green transit network. International Game Theory Review, 2016, vol. 18(2), p. 1640003.

4. Zakharov V., Krylatov A., Ivanov D. Equilibrium traffic flow assignment in case of two navigation providers. IFIP Advances in Information and Communication Technology, 2013, vol. 408, pp. 156-163.

5. Zakharov V., Krylatov A. Transit network design for green vehicles routing. Advances in Intelligent Systems and Computing, 2015, vol. 360, pp. 449-458.

6. Beckman M., McGuire C., Winsten C. Studies in economics of transportation. RM-1488. Santa Monica, RAND Corporation Publ., 1955, 232 p.

7. Sheffi Y. Urban transportation in networks: equilibrium analysis with mathematical programming methods. New Jersey, Prentice-Hall, Inc., Englewood Cliffs Press, 1985, 416 p.

8. Yang H., Huang H.-J. The multi-class, multi-criteria traffic network equilibrium and system optimum problem. Transportation Research Part B, 2004, vol. 38, pp. 1-15.

9. Krylatov A. Reduction of a minimization problem for a convex separable function with linear constraints to a fixed point problem. Journal of Applied and Industrial Mathematics, 2018, vol. 12(1), pp. $98-111$.

10. Krylatov A., Shirokolobova A. Equilibrium route flow assignment in linear network as a system of linear equations. Vestnik of Saint Petersburg University. Applied Mathematics. Computer Sciences. Control Processes, 2018, vol. 14, iss. 2, pp. 103-115.

11. Krylatov A., Zakharov V., Tuovinen T. Optimization models and methods for equilibrium traffic assignment. New York, Springer Intern. Publ., 2020, 239 p.

12. Krylatov A., Shirokolobova A. Projection approach versus gradient descent for network's flows assignment problem. Lecture Notes in Computer Science, 2017, vol. 10556, pp. 345-350.

Received: December 29, 2020.

Accepted: January 15, 2021. 
Authors' information:

Anastasiya P. Raevskaya - PhD in Physics and Mathematics, Associate Professor; a.raevskaya@spbu.ru

Alexander Y. Krylatov - Dr. Sci.n Physics and Mathematics, Professor; a.krylatov@spbu.ru

\title{
Нелинейная оптимизация для непрерывной оценки спроса на перемещение*
}

\author{
А. П. Раевская, А. Ю. Крылатов \\ Санкт-Петербургский государственный университет, Российская Федерация, \\ 199034, Санкт-Петербург, Университетская наб., 7-9
}

Для цитирования: Raevskaya A.P., Krylatov A. Y. Non-linear optimization for continuous travel demand estimation // Вестник Санкт-Петербургского университета. Прикладная математика. Информатика. Процессы управления. 2021. Т. 17. Вып. 1. С. 40-46.

https://doi.org/10.21638/11701/spbu10.2021.104

Модели и методы распределения транспортных потоков разрабатываются исследователями всего мира. Развитие этого научного направления вносит вклад как в теорию, так и в практику. В настоящей работе исследуется вопрос непрерывного решения задачи оценки спроса на перемещение посредством нелинейной оптимизации перераспределения транспортных потоков. Разработан подход в виде вычислительной методологии для решения оптимизационных сетевых задач такого рода. Доказана теорема единственности для определенного типа улично-дорожных топологий. Построены в явном виде отношения между спросом на перемещение и транспортным потоком для сети из непересекающихся маршрутов со специальными полиномиальными функциями времени движения. Полученные результаты вносят вклад в теорию, позволяют транспортным инженерам по-новому решать рассматриваемую проблему.

Ключевые слова: оценка спроса на перемещение, распределение транспортных потоков, нелинейная оптимизация, двухуровневая оптимизация.

Контактная информация:

Раевская Анастасия Павловна - канд. физ.-мат. наук, доц.; a.raevskaya@spbu.ru

Крылатов Александр Юръевич - д-р физ.-мат. наук, проф.; a.krylatov@spbu.ru $00062)$

* Работа выполнена при финансовой поддержке Российского научного фонда (проект № 20-71Вестник СПбГУ. Прикладная математика. Информатика... 2021. Т. 17. Вып. 1 